\title{
Cross Correlation Analysis of Gamma Exposure Rates and Rainfall, Hours of Saylight, Average Wind Speed in Gangneung Area
}

\author{
Hohwan Cha, Jaehwa Kim \\ Department of Physics, Gangneung-Wonju National University

\section{강릉 지역 공간 감마선량률과 강수량, 일조시간, 평균풍속 사이 교차 상관성 분석}

차호환, 김재화

강릉원주대학교 물리학과

\begin{abstract}
In this study, we analyze the cross correlation between Gamma exposure rates and Rainfall, Hours of daylight, Average wind speed using cross-correlation coefficient $\rho_{D C C A}$ and DCCA cross-correlation coefficient(DCCA $\rho$ ) method. Our data are measured simultaneous in Gangneung regional. First, we find the $\rho_{D C C A}$ between Gamma exposure rates and Rainfall is Day(3 7days) 0.57 0.48, Month(30days) 0.39, Season(90days) 0.34, Year(360days) 0.26, between Gamma exposure rates and Hours of daylight is Day $-0.20 \sim-0.23$, Month -0.22 , Season -0.17 , Year -0.13 , between Gamma exposure rates and Average wind speed is Day - 0.10 - 0.12 , Month - 0.11, Season - 0.05, Year 0.05. Second, our finding is cross- correlation between Gamma exposure rates and Rainfall, is no cross-correlation between Gamma exposure rates and Hours of daylight, Average wind speed.
\end{abstract}

Key Words : Gamma exposure rates, Cross correlation coefficient $\rho_{D C C A}$, DCCA $\rho$, DFA

\section{요 야}

본 논문은 강릉 지역에서 동일 기간에 기록된 공간 감마선량률과 강수량, 일조시간, 평균풍속 사이의 교차 상관 지 수 $\rho_{D C C A}$ 를 DCCA cross-correlation coefficient(DCCA $\rho$ )방법으로 구하여 교차 상관성을 분석하였다. 우리는 이 연구를 통해 다음의 사실을 알았다. 첫 번째, 공간 감마선량률과 강수량 사이 $\rho_{D C C A}$ 는 일(4 7일), 달(30일), 계절(90일), 년(360 일)에서 $0.57 \sim 0.48,0.39,0.34,0.26$, 공간 감마선량률과 일조시간 사이 $\rho_{D C C A}$ 는 일, 달, 계절, 년에서 $-0.20 \sim-0.23$, $-0.22,-0.17,-0.13$, 공간 감마선량률과 평균풍속 사이의 $\rho_{D C C A}$ 는 일, 달, 계절, 년에서 $-0.10 \sim-0.12,-0.11,-0.05,-0.05$ 이 다. 두 번째, $\rho_{D C C A}$ 를 통하여 공간 감마선량률과 강수량은 교차 상관성이 있으며 공간 감마선량률과 일조시간, 평균풍 속 사이에는 교차 상관성이 없다는 것을 확인하였다.

중심단어 : 공간 감마선량률, 교차 상관 지수 $\rho_{D C C A}, \mathrm{DCCA} \rho, \mathrm{DFA}$ 


\section{I. 서 론}

시계열 분석은 물리학, 생리학, 지진학, 금융공학, 기상학 등의 분야에서 여러 통계적 분석법에 의해 지 속적이며 폭넓게 연구되어 왔다. 이 연구들을 통하여 실제 데이터는 장거리 상관성과 교차 상관성을 가지 고 있다는 것이 밝혀졌다. ${ }^{[1-3]}$ 현재까지 이러한 상관성 들을 이용하여 여러 분야에서 다양한 현상들을 설명 하였으며, 최근에는 동시에 기록된 두 데이터 사이의 교차 상관 지수를 이용한 교차 상관성 연구가 지속적 으로 이루어지고 있다.[4-8]

일반적으로 초기의 장거리 상관성과 교차 상관성 을 연구하는 분석 방법들은 $\mathrm{ACF}$ (Auto-correlation function) ${ }^{[11]}, \mathrm{CCF}$ (Cross-correlation function) 가 있으며 이 방법들은 데이터가 정상적(Stationary)인 성질을 갖는 경우에 사용된다. 우리의 주 연구 대상은 비정상적 (Non-Stationary) 성질을 갖는 실제 데이터이므로 이 방 법들은 적합하지 않은 것으로 알려져 있다. 비정상적 (Non-Stationary) 성질을 갖는 데이터들의 시계열 분석 은 DFA(Detrended fluctuation analysis) ${ }^{[9,11]}$, DCCA(Detre-nded cross-correlation analysis $)^{[5]}$, DCCA $\rho$ (DCCA cross-correlation coefficient $)^{[7,8]}$ 방법이 가장 유용하다고 알려 져 있다. 이 방법들을 사용하여 장거리 상관성과 교차 상관성을 분석 할 수 있다. DFA, DCCA의 두 식으로 정의되는 DCCA $\rho$ 방법은 동시에 기록되고 장거리 상 관성을 갖는 두 실제 데이터 사이 교차 상관 지수를 구하는 방법이며 이 지수를 통해 시계열 사이의 교차 상관성을 분석한다. ${ }^{[7,8]}$

최근 세계 여러 도시나, 국내의 여러 도시에 대한 일부 기상요소 사이에 DCCA $\rho$ 방법을 이용한 교차 상관성을 연구한 논문들이 발표 되었으며 ${ }^{[8,10]}$ 그 결과 들은 매우 유용할 것이다. 이미 다양한 분야에서 연구 가 진행되고 있지만 공간 감마선량률에 관한 교차 상 관성 연구는 아직 이루어지지 않았다. 따라서 공간 감 마선량률에 관한 교차 상관성은 한시라도 빨리 연구 되어야 할 가치가 있을 것으로 보인다.

본 논문에서는 강릉 지역에서 기록된 공간 감마선 량률과 강수량, 일조시간, 평균풍속에 DCCA $\rho$ 방법을 적용하여 교차 상관 지수를 구하였고 이 결과를 이용
하여 교차 상관성을 분석한다.

\section{II. 대상 및 방법}

\section{1. 분석 대상}

DCCA $\rho$ 방법의 대상은 동시에 기록되어야 한다. 따라서 분석 대상은 2009년 1월 1일부터 2011년 12월 31 일까지 강릉 지역에 위치한 지방 방사능 측정소와 각 지방 기상청에서 관측한 공간 감마선량률과 강수 량, 일조시간, 평균풍속의 일별 데이터이다. 공간 감마 선량률은 지상으로부터 $1 \sim 1.2 \mathrm{~m}$ 높이에 설치된 섬광형 방사선 감시기 $[\mathrm{NaI}(\mathrm{Tl})]$ 를 통하여 한 시간 누적값으로 기록되며 평균값은 $11.78 \mu R / h$ 이다. 강수량, 일조시 간, 평균풍속은 기상청 홈페이지에 공개된 일별 데이 터를 이용하였다. ${ }^{[14]}$

\section{2. 분석 방법}

공간 감마선량률과 강수량, 일조시간, 평균풍속 데 이터를 DCCA $\rho$ 방법에 대하여 MATLAB 프로그램을 이용하여 코딩하였고 그 결과값인 교차 상관 지수를 그래프와 표로 나타내고 분석 하였다.

$\mathrm{ACF}$ 와 $\mathrm{CCF}$ 는 장거리 상관성과 교차 상관성을 연 구하는 가장 잘 알려진 방법들이다. 이 방법들을 정의 하기 위하여 두 개의 동시에 기록된 시계열 데이터의 편차를 $\left\{y_{i}\right\},\left\{y_{i}^{\prime}\right\}$ 라 한다. 여기서 $i=1, \ldots, N, k \leq N$ 이다. 각 시계열 데이터에 대한 $\mathrm{ACF}$ 는 다음과 같다.

$$
\begin{aligned}
& A(n)=\overline{\left(y_{k}-\mu\right)\left(y_{k+n}-\mu\right)} / \sigma^{2} \\
& A^{\prime}(n)=\overline{\left(y_{k}^{\prime}-\mu^{\prime}\right)\left(y_{k+n}^{\prime}-\mu^{\prime}\right)} / \sigma^{\prime 2} \\
& \mu=\overline{y_{i}}, \quad \mu^{\prime}=\overline{y_{i}^{\prime}}, \quad \sigma^{2}=\overline{\left(y_{i}-\mu\right)^{2}}, \quad \sigma^{\prime 2}=\overline{\left(y_{i}^{\prime}-\mu^{\prime}\right)^{2}}
\end{aligned}
$$

는 각각의 평균과 분산이고, $A(n) \sim n^{-\gamma}$, $A^{\prime}(n) \sim n^{-\gamma^{\prime}}, 0<\gamma, \gamma^{\prime}<1$ 이다. 각 시계열 데이터에 대한 $\mathrm{CCF}$ 는 다음과 같다.

$$
X(n)=\overline{\left(y_{k}-\mu\right)\left(y_{k+n}^{\prime}-\mu^{\prime}\right)} /\left(\sigma \sigma^{\prime}\right)
$$

여기서 $X(n) \sim n^{-\gamma_{\times}}, 0<\gamma_{\times}<1$ 이다.

Peng et al ${ }^{[9]}$ 에 의해 제안 된 $\mathrm{DFA}$ 를 정의하기 위하 여 어떤 시계열 데이터의 편차를 $\left\{y_{i}\right\}$ 라 한다. 편차의 
누적값은 $\quad Y_{k} \equiv \sum_{i=1}^{k} y_{i} \quad$ 이고, 여기서 $i=1, \ldots, N$, $k=1, \ldots, N$ 이다. $\mathrm{DFA}$ 정의의 첫 과정은 전체 데이터 $N$ 을 박스로 나누는 것이다. 두 번째 과정으로 $\tilde{Y}_{k, i}$ $(i \leq k \leq i+n)$ 를 정의한다. 이 값들은 각 박스 안 $Y_{k, i}$ 값들의 이차 다항식이고 "Local trend"라 한다. 세 번째 로 각 박스에서 "Detrended walk"라 정의 된 $\left(Y_{k}-\tilde{Y}_{k, i}\right)$ 를 이용하여 다음 식을 정의 한다.

$$
f_{D F A}^{2}(n, i) \equiv 1 /(n+1) \sum_{k=i}^{i+n}\left(Y_{k}-\tilde{Y}_{k, i}\right)^{2}
$$

마지막으로 평균을 구하는 것으로 $\mathrm{DFA}$ 가 정의 된 다.

$$
F_{D F A}^{2}(n) \equiv(N-n)^{-1} \sum_{i=1}^{N-n} f_{D F A}^{2}(n, i) \sim n^{\alpha}
$$

DCCA 방법은 Podobnik and Stanley에 의해 제안되 었다. ${ }^{[5]}$ 두 시계열 데이터의 편차가 각각 $\left\{y_{i}\right\},\left\{y_{i}^{\prime}\right\}$ 이 면, 편차의 누적값은 $Y_{k} \equiv \sum_{i=1}^{k} y_{i}, \quad Y_{k}^{\prime} \equiv \sum_{i=1}^{k} y_{i}{ }^{\prime}$, Local trend는 $\tilde{Y}_{k, i}, \widetilde{Y}_{k, i}{ }^{\prime}(i \leq k \leq i+n)$, 여기서 $i=1, \ldots, N$, $k=1, \ldots, N$ 이다. 각 박스에 대한 공분산은

$$
f_{D C C A}^{2}(n, i) \equiv 1 /(n+1) \sum_{k=i}^{i+n}\left(Y_{k}-\widetilde{Y}_{k, i}\right)\left(Y_{k}^{\prime}-\tilde{Y}_{k, i}{ }^{\prime}\right) \quad \cdot(6)
$$$$
\text { 이고, 전체 } N-n \text { 박스에 대한 평균값은 }
$$$$
F_{D C C A}^{2}(n) \equiv(N-n)^{-1} \sum_{i=1}^{N-n} f_{D C C A}^{2}(n, i) \sim n^{2 \lambda}
$$

로 정의 된다. 여기서 $\gamma$ 가 장거리 교차 상관성을 나 타낸다. 그러나 $\gamma$ 가 교차 상관성 레벨을 나타내지는 못한다. 따라서 G. F. Zebende에 의해 제안된 DCCA $\rho$ 방법의 교차 상관 지수 $\rho_{D C C A}$ 를 다음과 같이 정의한 다. ${ }^{[7]}$

$$
\rho_{D C C A}=\frac{F_{D C C A}^{2}(n)}{F_{D F A\left\{x_{i}\right\}} F_{D F A\left\{x_{i}^{\prime}\right\}}(n)}
$$

$\rho_{D C C A}$ 는 $-1 \leq \rho_{D C C A} \leq 1$ 이다. 두 시계열에 대하 여 $\rho_{D C C A}=1$ 이면 Perfectly cross-correlation이고 $\rho_{D C C A}$ $=-1$ 이면 Perfectly anti-cross-correlation이다. $\rho_{D C C A}=$ 0 이면 No cross-correlation이고 표 1에 정리하였다.

이 지수값들의 의미는 그림 1 을 이용하여 설명할 수 있다. 그림 1 은 서로 다른 두 Random data 1, 2를 생
성하여 DCCA $\rho$ 방법에 적용하여 $\rho_{D C C A}$ 를 나타낸 그 래프이다. 두 시계열 값에 Random data1을 넣고 DCCA $\rho$ 방법에 적용하면 $\rho_{D C C A}$ 는 1 이 나오며, 서로 다른 Random data 1,2 적용하면 $\rho_{D C C A}=0$ 이 나온다. 또 Random data 1 과 Reverse random data 1 에 적용하면 $\rho_{D C C A}=-1$ 이 나온다. 즉 Perfectly cross-correlation은 동일한 시간에 대하여 두 시계열이 동일한 경향을 갖 음을 의미하며, Anti-cross-correlation 은 동일한 시간에 대하여 두 시계열이 반대되는 경향을 가짐을 의미한 다. No cross-correlation은 동일한 시간에 대하여 두 시 계열이 교차 상관성이 전혀 없다는 것을 의미한다.

Table 1. DCCA cross-correlation coefficient $\rho_{D C C A}$ in terms of cross-correlation.

\begin{tabular}{c|c}
\hline$\rho_{D C C A}$ & Condition \\
\hline \hline 1 & Perfect cross-correlation \\
\hline 0 & No cross-correlation \\
\hline-1 & Perfect ant i cross-correlation \\
\hline
\end{tabular}

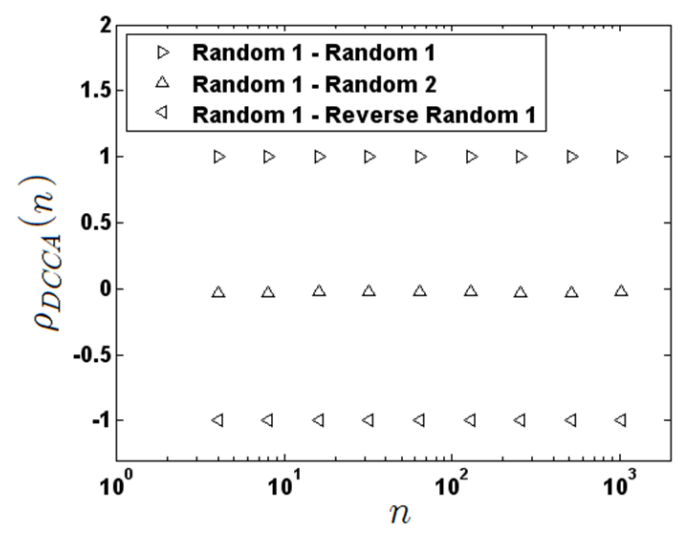

Fig 1. DCCA cross-correlation coefficient $\rho_{D C C A}$ between Random data 1 - Random data $1\left(\rho_{D C C A}=1\right)$, Random data 1 - Random data $2\left(\rho_{D C C A}=0\right)$ and Random data 1 - Reverse Random data $2\left(\rho_{D C C A}=-1\right)$.

\section{III. 실험결과}

DCCA $\rho$ 방법을 강릉 지역 공간 감마선량률과 강 수량, 일조시간, 평균풍속의 실제 데이터에 직접 적용 하여 나온 값을 표와 그래프로 나타내고 이 결과를 이 용하여 분석 한다. 
먼저 강릉 지역에서 동일 기간에 기록된 공간 감 마선량률과 강수량, 일조시간, 평균풍속 사이의 교차 상관 지수 $\rho_{D C C A}$ 를 DCCA $\rho$ 방법으로 구하여 그림 2 에 나타내었다. $y$ 축은 식(8)에 의하여 계산된 $\rho_{D C C A}$ 값 이며, $x$ 축 $n$ 은 각 스케일의 크기 $n=[3,4,5, \cdots \cdots$, $29,30],[60,90,120, \cdots \cdots, 360]$ 이다. 그림 2에서 공간 감마선량률과 강수량 사이의 교차 상관성은 작은 스 케일에서 강한 교차 상관성을 보이며 스케일이 증가 할수록 약한 교차 상관성을 보이며, 공간 감마선량률 과 일조시간 사이의 교차 상관성은 작은 스케일에서 매우 약한 교차 상관성을 보이다가 스케일이 증가하 면서 거의 사라지는 것으로 분석된다. 또 공간 감마선 량률과 평균풍속 사이의 교차 상관성은 모든 스케일 에서 없는 것으로 분석된다.

다음으로 각 스케일 $n$ 이 시간에 해당하는 것을 이 용하여 표 2와 같이 일(3 7일), 달(30일), 계절(90일), 년 (360일)에 대하여 분석할 수 있다. 공간 감마선량률과 강수량 사이 $\rho_{D C C A}$ 는 일, 달, 계절, 년에서 $0.57 \sim 0.48$, $0.39,0.34,0.26$ 이며, 일간에서 강한 교차 상관성을 보 이며 연간으로 갈수록 약한 교차 상관성을 보인다. 공 간 감마선량률과 일조시간 사이 $\rho_{D C C A}$ 는 일, 달, 계절, 년에서 $-0.20 \sim-0.23,-0.22,-0.17,-0.13$ 이며, 일간, 월간 에서 매우 약한 교차 상관성을 보이다가 계절, 연간에 서 거의 사라진다. 공간 감마선량률과 평균풍속 사이 의 $\rho_{D C C A}$ 는 일, 달, 계절, 년에서 $-0.10 \sim-0.12,-0.11$, $-0.05,-0.05$ 이며, 모든 기간에서 교차 상관성이 없음을

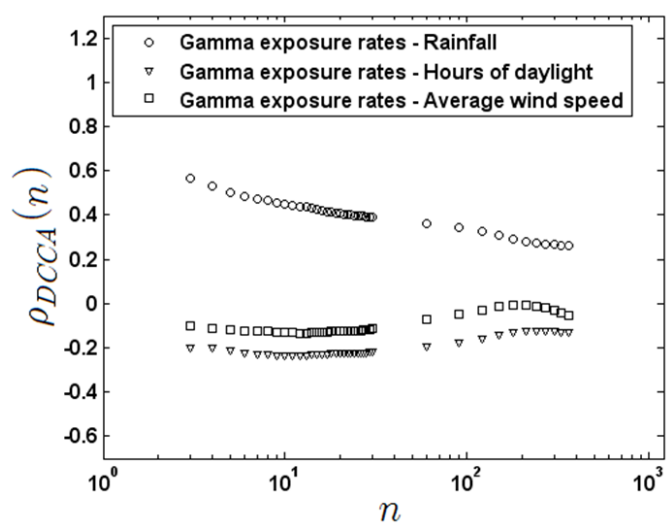

Fig 2. DCCA cross-correlation coefficient $\rho_{D C C A}$ between Gamma exposure rates - Rainfall, Gamma exposure rates Hours of daylight and Gamma exposure rates - Average wind speed.
알 수 있다. 이 분석 결과로 보아 Wash-out 현상처 럼 비나 눈이 올 때 공간 감마선량률이 증가하며 일조 시간과 평균풍속은 공간 감마선량률에 거의 영향을 미치지 않음을 의미한다.

마지막으로 그림 3 과 같이 공간 감마선량률과 강 수량, 일조시간, 평균풍속을 셔플링하여 교차 상관 지 수 $\rho_{D C C A}$ 를 구하였으며 모두 No cross-correlation한 결

Table 2. Values of $\rho_{D C C A}$ with seasonal components.

\begin{tabular}{c|ccccc}
\hline & \multicolumn{5}{|c}{ Says(3 7) } \\
\cline { 2 - 6 } Real data & 3 & 4 & 5 & 6 & 7 \\
\hline \hline $\begin{array}{c}\text { Gamma exposure rates } \\
\text { - Rainfall }\end{array}$ & 0.57 & 0.53 & 0.50 & 0.49 & 0.48 \\
\hline $\begin{array}{c}\text { Gamma exposure rates } \\
\text { - Hours of dayl ight }\end{array}$ & -0.20 & -0.20 & -0.21 & -0.22 & -0.23 \\
\hline $\begin{array}{c}\text { Gamma exposure rates } \\
\text { - Average wind speed }\end{array}$ & -0.10 & -0.12 & -0.12 & -0.12 & -0.12 \\
\hline
\end{tabular}

\begin{tabular}{|c|c|c|c|}
\hline Scale & Month & Season & Year \\
\hline Real data & 30 & 90 & 360 \\
\hline $\begin{array}{c}\text { Gamma exposure rates } \\
\text { - Rainfall }\end{array}$ & 0.39 & 0.34 & 0.26 \\
\hline $\begin{array}{l}\text { Gamma exposure rates } \\
\text { - Hours of daylight }\end{array}$ & -0.22 & -0.17 & -0.13 \\
\hline $\begin{array}{l}\text { Gamma exposure rates } \\
\text { - Average wind speed }\end{array}$ & -0.11 & -0.05 & -0.05 \\
\hline
\end{tabular}

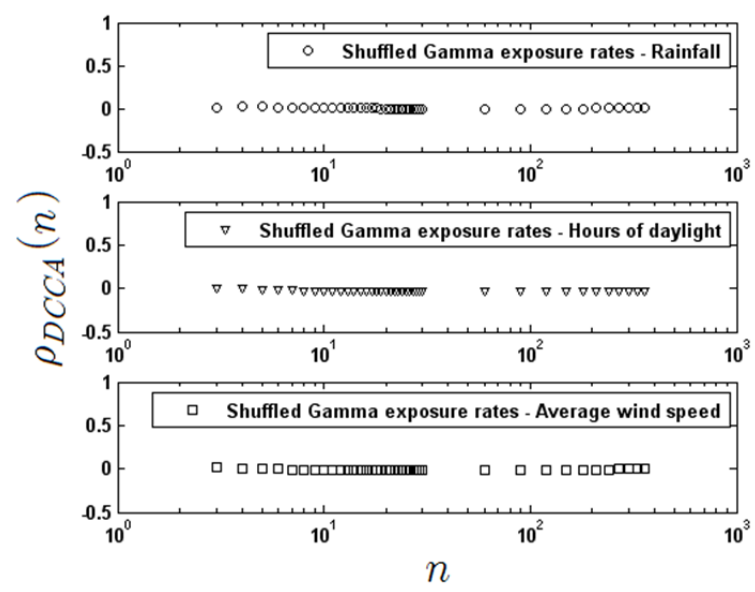

Fig 3. DCCA cross-correlation coefficient $\rho_{D C C A}$ between Shuffled Gamma exposure rates - Shuffled Rainfall $\left(\rho_{D C C A}=0\right.$ ), Shuffled Gamma exposure rates - Shuffled Hours of daylight $\left(\rho_{D C C A}=0\right)$ and Shuffled Gamma exposure rates 
Shuffled Average wind speed $\left(\rho_{D C C A}=0\right)$.

과인 0 이 나왔다. 이것으로 본 논문에서 사용된 원 래의 시계열만이 상관성을 갖는다는 것을 검증하였다.

\section{$\mathrm{IV}$. 고 찰}

본 논문은 DCCA $\rho$ 방법을 사용하여 두 시계열 사 이의 교차 상관 지수를 구하여 교차 상관성을 분석하 였다. DCCA $\rho$ 방법으로 두 시계열 사이의 교차 상관 지수 $\rho_{D C C A}$ 를 구할 수 있고, 이 $\rho_{D C C A}$ 의 결과값을 이 용하여 교차 상관성을 분석 하는 것이다. 우리는 이 방법을 공간 감마선량률과 상관성이 있다고 알려진 강수량과 상관성이 없다고 알려진 일조시간, 평균풍속 에 적용하였다. 비나 눈이 온 뒤 측정값이 높게 나오 는데 이것을 Wash-out이라고 한다. 강수량은 공간 감 마선량률의 측정값에 영향을 주는 것으로 알려져 있 다. 하지만 공간 감마선량률과 강수량이 어느 정도의 상관성을 갖는지 말하는 하는 것은 쉽지 않다. DCCA $\rho$ 방법은 그 문제점을 해결하는데 그 의의가 있다고 할 수 있다. 두 시계열의 교차 상관성을 수치화 한다 면 상관성 정도를 쉽게 이해 할 수 있을 것이다.

우리는 DCCA $\rho$ 방법을 강릉 지역에서 2009년부터 2011년까지 측정된 공간 감마선량률과 강수량, 일조시 간, 평균풍속의 실제 데이터에 적용을 하여 강수량, 일 조시간, 평균풍속이 공간 감마선량률과 어느 정도의 교차 상관성을 갖는지 분석하였다. 분석 결과는 시간 에 대한 $\rho_{D C C A}$ 를 그린 그래프와 표를 통하여 할 수 있 으며 다음과 같이 결론을 내릴 수 있다.

강릉 지역 공간 감마선량률과 강수량 사이 $\rho_{D C C A}$ 는 $0.57 \sim 0.48$ (일), 0.39 (월), 0.34 (계절), 0.26 (년)이다. 따라 서 교차 상관성은 일간에 대해 강한 교차 상관성이 있 음을, 연간으로 갈수록 교차 상관성이 약해짐을 알 수 있다. 이것은 비나 눈이 올 때 공간 감마선량률이 증 가함을 의미하며 일반적으로 알려진 Wash-out 현상임 을 확인하였다. 공간 감마선량률과 일조시간 사이 $\rho_{D C C A}$ 는 $-0.20 \sim-0.23$ (일), -0.22 (월), -0.17 (계절), -0.13 (년), 공간 감마선량률과 평균풍속과 사이 $\rho_{D C C A}$ 는 0.10 -0.12(일), -0.11(월), -0.05(계절), -0.05 (년)이다. 공간 감마선량률과 일조시간, 공간 감마선량률과 평균풍속 과 사이의 교차 상관성은 매우 약함을 확인하였으며,
이것은 일조시간과 평균풍속이 공간 감마선량률에 거 의 영향을 주지 않음을 의미한다.

본 논문에 사용된 DCCA $\rho$ 방법은 자연 방사선 분 야뿐만이 아니라 시계열 데이터를 갖는 모든 분야에 적용이 가능하다. 금융공학의 주가 ${ }^{[8]}$, 방사선학의 피폭 선량[12], 흡수 스펙트럼 ${ }^{[13]}$ 에 관계된 데이터들과의 교 차 상관성을 정량화하는데 적용할 수 있을 것으로 사 료된다.

\section{$\mathrm{V}$ 결 론}

본 연구의 결과로 공간 감마선량률과 강수량은 교 차 상관성이 있으며 일간에 대해 강한 교차 상관성이 있음을, 연간으로 갈수록 교차 상관성이 약해짐을 알 수 있다. 또한 공간 감마선량률과 일조시간, 평균풍속 사이에는 교차 상관성이 없다는 것을 확인하였다.

공간 감마선량률과 다른 시계열 사이의 DCCA $\rho$ 방 법으로 구한 교차 상관 지수 $\rho_{D C C A}$ 를 이용한 교차 상 관성 분석은 자연 방사선 분야에서 매우 중요한 역할 을 할 것이며 앞으로 더 다양한 시계열 사이에서 연구 가 지속적으로 이루어질 것이다.

$\mathrm{DCCA} \rho$ 방법이 소개된지 얼마 되지 않았으므로 아직은 논문이 그리 많지 않은 편이다. 현재는 기상 요소 사이에서의 교차 상관성 연구가 가장 활발하 다. ${ }^{[8,10]}$ 하지만 본 논문과 같이 자연 방사선 분야에 이 방법을 적용한 것처럼 앞으로 다양한 학문에서 활발 하게 연구될 것으로 사료된다.

\section{참고문헌}

[1] J. Feder, Fractals, Plenum Press, New York, 1988.

[2] M. F. Barnsley, Fractals everywhere, Academic Press, 1993.

[3] A. Bunde and S. Havlin, Fractals in Science, Springer, Berlin, 1994.

[4] B. Podobnik, Z.-Q. Jiang, W.-X. Zhou and H. E. Stanley, Statistical tests for power-law cross-correlated processes, Phys. Rev. E, Vol 84, No 066118, 2011.

[5] B. Podobnik and H. E. Stanley, Detrended cross-correlation analysis : A new method for analyzing two nonstationary time series, Phys. Rev. Lett., Vol 100, No 084102, 2008. 
[6] D. Horvatic, H. E. Stanley and B. Podobnik, Detrended cross-correlation analysis for non-stationary time series with periodic trends, Europhys. Lett., Vol 94, No 18007, 2011.

[7] G. F. Zebende, DCCA cross-correlation coefficient, quantifying level of cross-correlation, Physica A, Vol 390, No 614, 2011.

[8] R.T. Vassoler and G.F. Zebende, DCCA cross-correlation coefficient : Quantifying level of cross-correlation, Physica A, Vol 391, No 2438, 2012.

[9] C.-K. Peng, S. V. Buldyrev, S. Havlin, M. Simons, H. E. Stanley and A. L. Goldberger, Mosaic organization of DNA nucleotides, Phys. Rev. E, vol 49, No 1685, 1994.

[10] G. Lim, K. Kim, J.-K. P and K.-H. C, J. Dynamical Analyses of the Time Series for the Temperature and the Humidity, Korean Phys. Soc., Vol 62, No 193, 2013.

[11] Hohwan Cha, Jaehwa Kim, Time Series Analysis of Gamma exposure rates in Gangneung Area, Journal of the Korean Society of Radiology, Vol 7, No 1, 2013.

[12] Minsun Yu, Jaeseung Lee, Inchul Im, Evaluation of Approximate Exposure to Low-dose Ionizing radiation from Medical Images using a computed Radiography (CR) System, Journal of the Korean Society of Radiology, Vol 6, No 6, 2012.

[13] Kyotae Kim, Sangsik Kang, Sicheul Noh, Bongjae Jung, Changhoon Cho, Yeji Heo, Jikoon Park, Absorbed Spectrum Comparison of Lead and Tungsten in Continuous X-ray Energy using Monte Carlo Simulation, Journal of the Korean Society of Radiology, Vol 6, No 6, 2012.

[14] http://www.kma.go.kr/ 